\title{
Transperineal bulboprostatic anastomotic repair of pelvic fracture urethral distraction defect and role of proximal urethral mobilisation: A retrospective study in $\mathbf{7 6}$ patients
}

\author{
Sharma Rakesh, Mitra Subrata K, Majee Prasenjit, Gill Tejpal S, \\ Dey Ranjan K, Basu Supriya, Das Ranjit K \\ Department of Urology, R G KAR Medical College \& Hospital, West Bengal university of health sciences, India
}

\begin{abstract}
Objective: We present our experience with transperineal bulboprostatic anastomotic procedure and compare the results with age of patients, length of urethral stricture, effect of previous treatment and need for urethral mobilisation.

Materials and Methods: We retrospectively reviewed the outcome of 76 patients who underwent perineal urethroplasty procedure for traumatic stricture in our institute. Perineal urethroplasty with full distal urethral mobilisation was done in 30 patients. In 46 patients, minimal distal bulbar urethral mobilization was done coupled with more extensive proximal mobilization and use of other techniques like corporal separation \& inferior pubectomy. Age, length of stricture and urethral mobilisation required during reconstruction were documented. The clinical outcome was measured by patient's symptomatic improvement and objective measurements like uroflowmetry and retrograde urethrogram.

Result: Out of the total 76 cases that underwent transperineal urethroplasty procedure, 69 (90.78\%) were successful. Perineal urethroplasty with full distal mobilisation procedure showed a success rate of $83.33 \%$, perineal anastomosis with more extensive proximal urethral mobilisation had a success rate of $95.65 \%$.

Conclusion: The success rate of perineal urethroplasty with proximal urethral mobilisation procedure for posttraumatic stricture urethra is excellent and majority of the failures occur in prepubescent boys, long urethral stricture, in those undergoing secondary repair and in those cases in which more distal urethral mobilisation done.
\end{abstract}

Keywords: Proximal urethral mobilisation, pelvic fracture, perineal urethroplasty, urethral stricture

\section{Introduction}

Posterior urethral injury most commonly occurs as a consequence of pelvic fracture and may occur in up to $10 \%$ of cases.[1]

In 1977, Turner-Warwick popularized a distinction between simple and complex posterior urethral strictures resulting from pelvic fracture urethral distraction defect (PFUDD). Most post-traumatic strictures are simple and are suitable for one stage transperineal bulboprostatic anastomosis. Complex stricture associated with fistula, false passage, chronic periurethral abscess, osteomyelitis or damage to bladder neck may require a more extensive abdominoperineal approach.[2]

The aim of surgical reconstruction for urethral stricture is to provide an adequate calibre, compliant and stable urethra. In 1983, Webster and Raman popularized a more elaborate perineal approach for the reconstruction of pelvic fracture related urethral distraction injury in which proximal urethral mobilization was done through steps of corporal splitting, inferior pubectomy and supracrural urethral rerouting, as needed, to bridge urethral defect for tension free urethral anastomosis .[3] In 1990s, this approach became the gold standard for the treatment of traumatic posterior urethral stricture.[4]

In 2003, Flynn et al. reported the long-term result of this progressive one stage perineal anastomosis repair in 120 patients with PFUDD.[4] This technique was successful in 95\% of adults, 73\% of prepubescent boys and $86 \%$ of patients undergoing secondary repair.

Conversely, Kizer et al. suggested that ancillary procedures such as corporal splitting, inferior pubectomy and corporal rerouting are less required for successful posterior urethral reconstruction. [5]

Earlier reports regarding the role of proximal mobilisation in transpeirneal bulboprostatic anastomotic repair of PFUDD are not uniform. Some authors recommended this procedure while others suggested that proximal urethral mobilisation is seldom required for successful posterior urethral reconstruction. Also, records of most of the previous studies on measurement of outcome after urethroplasty relied on qualitative data in follow up rather than quantitative data and there are very few studies from developing countries (where incidence of PFUDD is more) in comparison to those from developed countries. 
Therefore, we planned to retrospectively review our experience in Indian population that underwent transperineal bulboprostatic anastomosis, in respect of patient age, length of urethral stricture, effect of previous treatment and effect of distal/proximal urethral mobilisation

\section{Materials And Methods}

A total of 76 male patients, who underwent transperineal bulboprostatic anastomotic urethroplasty for traumatic posterior urethral stricture, at our institute between January 2006 and December 2012 were retrospectively reviewed. Average patient age was 34 (range 5-68) years. Blunt injury with pelvic fracture was caused by roadside accidents in all the patients. Preoperative evaluation included history, physical examination, complete urine analysis, urine culture, retrograde and voiding cystourethrography. The length of stricture was measured by a combined film of retrograde urethrography and micturating cystourethrography, and was also confirmed by urethroscopy and antegrade cystourethroscopy via suprapubic tract, simultaneously at the time of surgery. The malleable semirigid strip was used for measurement. Delayed transperineal bulboprostatic urethroplasty was performed 3-12 months (mean 5 months) after pelvic injury or previous failed urethroplasty. Out of 76 patients, 18 had previously undergone internal urethrotomy and 20 had previously undergone perineal urethroplasty procedure. Broad spectrum antibiotics were given before induction of anesthesia in all patients.

\section{Urethral reconstruction techniques}

All the patients were placed in exaggerated lithotomy position. The operative technique comprised of sequential maneuvers to achieve a tension-free anastomosis.

\section{Perineal anastomosis with full distal urethral mobilisation (30 patients, group 1)}

All the patients underwent vertical perineal incision. The bulbar urethra was completely mobilized and transected at the distal extent of the stricture. The stricture was excised under the guidance of metallic sound in the proximal urethra through the suprapubic cystostomy tract. Periurethral fibrosis was accessed. All scars and fibrotic tissue occupying the distraction defect were excised with a scalpel blade.

\section{Perineal anastomosis with proximal urethral mobilisation (46 patients, group II)}

In rest 46 patient we did very little distal urethral mobilisation only $2-2.5 \mathrm{~cm}$ and not even up to penoscrotal junction. We did vigorous proximal prostatic urethral mobilisation coupled with wide inferior pubectomy with or without crural separation. spatulation.

We mobilised and resected all fibrous tissue up to verumontanum and did anastomosis after

In Corporal Separation manoeuvre, Cavernosa septum was incised in midline plane beginning from crus to approximately $4-5 \mathrm{~cm}$ and distal urethra was inserted through the septum. This manoeuvre reduced the tension of end to end anastomosis.

In Inferior Pubectomy manoeuvre, after displacing the dorsal vein, a wedge of bone was excised from the inferior aspect of the pubis. This allows the urethra to be redirected cephalad resulting in an additional 1-2 $\mathrm{cm}$ of apparent urethral length. Haemostasis was achieved with bone wax.

In all cases, distal urethral end spatulated at 12 o'clock position(ventral) and proximal urethra spatulated at 6 o'clock position (dorsal) to achieve anastomosis of approximately $40 \mathrm{Fr}$. A tension-free mucosa to mucosa anastomosis was performed with eight interrupted sutures of 4-0 polyglycolic acid over a 18-F silicon catheter. Corrugated drains were placed which were removed after 48 hours of surgery. Stitches were removed on the eighth postoperative day. Pericatheter retrograde urethrogram was performed 3 weeks after repair, and if there was no extravasation, the urethral catheter was removed. smoothly.

Suprapubic catheter was removed after 7th day of removal of urethral catheter, when patient voided

\section{Outcome analysis}

Postoperative retrograde urethrogram was performed at 3 weeks, 3 months and 12 months after surgery. The uroflowmetry was done at yearly follow up. Charts were reviewed for age of patients, prior treatment, Proximal urethral mobilisation used during reconstruction, length of defect and erectile function. Surgical outcome was analyzed. The mean follow-up period was 26 months (range 12-42 months). Urethroplasty was considered successful when the patient was voiding well and did not require any further intervention.

Statistical analysis was done by using chi-square test. 


\section{Results}

In this study, 32 patients had bulbomembranous, 28 had membranous and 16 had bulboprostatic strictures . Out of 76 perineal urethroplasty procedures, 69 (90.78\%) were successful and $07(09.21 \%)$ were unsuccessful. Perineal anastomosis with distal urethral mobilisation was successful in $83.33 \%(25 / 76)$ of the patients and unsuccessful in $16.66 \%$ (5/30) of the patients [Table 1]. The difference in success rate between the two groups was found to be statistically significant $(p<0.05)$. Patients with bulbomembranous stricture had better success rate than those with membranous and bulboprostatic strictures in our study.

Success rate was $80 \%$ in five patients of age 5-15 years with statistically significant difference between $<15$ years of age and other groups $(P<0.05)$ [Table 2].

Success rate according to stricture length showed that short stricture had a better success rate compared to larger one but it also showed a statistically insignificant difference between urethral stricture length between $3-10$ and $<3 \mathrm{~cm}(P>0.05)$ [Table 3].

Success rate was $94.73 \%$ in patients who had not undergone previous treatment and $86.84 \%$ in patients who had undergone previous treatment and was statistically insignificant $(P>0.05)$ [Table 4].

\section{Continence}

All the patients were continent after urethroplasty procedure.

\section{Effect on erectile dysfunction}

Data on preoperative and postoperative erectile functions were available in 70 patients. All stated that they were sexually active before trauma and 28 patients $(40 \%)$ reported significant erectile dysfunction after the trauma. After urethroplasty, 6 patients $(8.57 \%)$ had diminished erectile function. Details of patients' evaluation and treatment records of the erectile dysfunction were not available.

\section{Discussion}

In developing countries, more patients are reported with PFUDD due to prevalent agricultural activity. Also, accidents on the work site have not dramatically lessened and bicycles and motor cycles are the most popularly used vehicles.[6]

Surgery for posterior urethral stricture is beset with problems of access, limited urethral length, surrounding fibrosis and the small caliber of the bulbar urethra that is susceptible to ischemic insult.[7]

Optimal timing (immediate vs. delayed) and surgical approach (endoscopic vs. open) of PFUDD remain controversial. Some advocate immediate urethral realignment $[9,10]$ and some suggest suprapubic cystostomy alone at the time of injury with delayed repair of the ensuring distraction defect.[11] There are circumstances in which immediate surgical exploration with pelvic hematoma evacuation and urethral realignment is generally indicated. These include concomitant bladder neck injury, severe prostatomembranous dislocation with pie in the sky bladder or rectal injury.[2,11] Immediate open realignment of these injuries is associated with an unacceptable high morbidity and a high incidence of recurrent stricture (69\%), urinary incontinence (20\%) and erectile dysfunction $(40 \%)$.

In our experience and as reported by others, delayed repair is invariably accomplished with a perineal approach resulting in stricture free healing and minimal associated morbidity.[3,11,12,13,14]

Delayed endoscopic cut to the light techniques for PFUDD has been performed primarily for short stricture.[15] The exact role of this approach needs to be established with respect to which distraction defects (in terms of length, etiology and prior treatment) are amenable to this management and what the optimal timing for this intervention should be.[4] Many of these patients subsequently require urethrotomy and self-calibration and this outcome must be objectively compared to contemporary series of delayed perineal repair with their predictable success rate in excess of $90 \%$ and minimal morbidity.[3,11,14] Furthermore, as in the series of delayed perineal repair, successful outcome should be defined as urethral patency independent of periodic selfcalibration. [3,11,14]

We evaluated our results according to factors that are reported to influence the result of urethroplasty, which are patient's age, stricture length and previous treatment.

Children and prepubescent boys in our study had a lower success rate than that of adults, similar to some earlier reports. Prepubescent patients may have insufficient vascular connection in the glans, resulting in inadequate retrograde blood flow to the distally based bulbar urethral flap. This compromised retrograde blood flow to the anastmotic site and may explain the lower success rate.[7] For this reason, posterior urethroplasty in children still represents a difficult problem. In our series, children and preadolescent boys (5-15 years) showed a lower success rate of $80 \%$, whereas adults had a success rate of more than $90 \%$ and it was statistically significant.

In our study, success rates were $95.23,91.66,88.89$ and $84.61 \%$ for $<1,1-2,2-3$ and $>3 \mathrm{~cm}$ stricture lengths, respectively. The relation of the success rate to stricture length showed that short stricture had a better 
success rate than larger one but not statistically significant. Strictures of 1-2 or 2-3 cm lengths had similar success rate.

Koraitim[8] suggested that the length of bulbar urethra may be a primary factor influencing the surgical steps and the outcome of bulboprostatic anastomosis. In the contrary in our study we did very less distal urethral mobilisation just 2-2.5 cm and not even up to penoscrotal junction. In our study, the success rate was higher in patients who had undergone more vigorous proximal prostatic urethral mobilisation and had not undergone previous treatment.

Most of our patients underwent perineal urethroplasty with proximal urethral mobilization and the success rate was high $(95.65 \%)$.

In the contrary Kizer et al.[5] reported that $67 \%$ of patients requiring posterior urethroplasty were managed by direct anastomosis after scar excision and urethral mobilization alone without any ancillary procedure. Distal mobilization of bulbous urethra from external sphincter to penoscrotal junction is known to provide $4-5 \mathrm{~cm}$ of urethral length. This step alone should be sufficient to allow tension-free reconstruction in the majority of posterior urethral injuries.[5]

Recurrence of stricture is troublesome during follow up. The major cause of recurrence is the incomplete excision of the scar tissue around the urethra during surgery, which resulted in contracture of postoperative scar. Extensive mobilization of distal urethra causes ischemia at the tip of the urethral stump that is to be anastomosed. This is observed visibly as there is less bleeding.But, when we mobilise the stump less there is more vascularity as observed by a constant trickle of blood from the stump. In addition prostatic urethra is also very vascular and mucosa to mucosa anastomosis gives excellent result.

The limitation of this study was that our institution is a tertiary care center and very large numbers of the patients included in this study were referred from other hospitals. So, details of initial trauma severity, investigations and treatment were limited. Furthermore, in this retrospective study, detailed evaluation and treatment records for the erectile dysfunction were not available.

\title{
V. Conclusion
}

The results of perineal anastomotic repair of PFUDD are excellent. The progressive perineal urethroplasty approach progressing sequentially through Proximal urethral mobilization, corporal body separation, inferior pubectomy and supracrural rerouting, enables tension-free anastomosis in defects up to 10 $\mathrm{cm}$. Majority of failures occur in prepubescent boys and those undergoing secondary repair.

\section{Acknowledgments}

study.

We are highly thankful to the patients, paramedical staff and above all to God for their help in this

\author{
Footnotes \\ Source of Support: Nil \\ Conflict of Interest: None.
}

\section{References}

[1]. Glass RE, Flynn JT, King JB, Blandy JP. Urethral Injury and fracture pelvis. Br J Urol. 1978;50:578-82. [PubMed: 753510]

[2]. Turner-Warwick R. Complex traumatic posterior urethral Stricture J Urol. 1977;118:564-74.

[3]. Webster GD, Ramon J. Repair of Pelvic fracture posterior urethral defects using an elaborated perineal approach: experience with 74 cases. J Urol.1991;145:744-8. [PubMed: 2005693]

[4]. Flynn BJ, Delvecchio FC, Webster GD. Perineal repair of pelvic fracture urethral distraction defects experience in 120 patients during the last 10 years. J Urol.2003;170:1877-80. [PubMed: 14532797]

[5]. Kizer WS, Armenakas NA, Brandes SB, Cavalcanti AG, Santucci RA, Morey AF. Simplified reconstruction of posterior urethral disruption defects.Limited role of supracrural rerouting. J Urol. 2007;177:1378-82. [PubMed: 17382736]

[6]. Barbagli G. History and evaluation of transpublic urethroplasty, a lesson for young urologists in training. Eur Urol. 2007;52:12902. [PubMed: 17630102]

[7]. Fu Q, Zhang J, Sa YL, Jin SB, Xu YM. Transperineal bullboprostatic anastomosis in patients with simple traumatic posterior urethral stricture: a retrospective study from referral urethral center. Urology. 2009;74:1132-6. [PubMed: 19716593]

[8]. Koraitim MM. Gapometry and anterior urethrometry in the repair of posterior urethral defects. J Urol. 2008;179:187981. [PubMed: 18353388]

[9]. Follis HW, Koch MO, McDougal WS. Immediate management of prostomembranous urethral disruption. J Urol. 1992;147:125962. [PubMed: 1569663]

[10]. Herschorn S, Thijssen A, Radomski SB. The value of immediate or early catheterization of the traumatized posterior urethra J Urol. 1992;48:1428-31.

[11]. Webster GD, Mathes GL, Selli C. Prostomembranous urethral injuries; A review of the literature and a rational approach to their management. J Urol.1983;130:898-902. [PubMed: 6355512]

[12]. McAninch JW. Traumatic injuries to the urethra. J Trauma. 1981;21:291-7. [PubMed: 7218395]

[13]. Morey AF, McAninch JW. Reconstruction of posterior urethral disruption injuries: outcome analysis in 82 patients. J Urol. 1997;57:506-10.[PubMed: 8996343] 
[14]. Corriere JN. I stage delayed bulbo prostatic anastomotic repair of posterior urethral rupture: 60 patients with 1-year follow up. J Urol. 2001;165:404-7.[PubMed: 11176383]

[15]. Dogra PN, Nabi G. Core through urethrotomy using the neodymium: YAG Laser for obliterative urethral stricture after traumatic urethral disruption and/or distraction defect: Long term outcome. J Urol. 2002;167:543-6. [PubMed: 11792915]

\section{Figures and Tables}

Table 1

Success rate according to surgical techniques

\begin{tabular}{|l|l|l|l|}
\hline Group & $\begin{array}{l}\text { No. of } \\
\text { patients }\end{array}$ & Surgical procedure & Success rate \\
\hline 1. & 30 & Perineal anastomosis with distal urethral mobilisation & $25(83.33)$ \\
\hline 2. & 46 & Perineal anastomosis with proximal urethral mobilisation & $44(95.65)$ \\
\hline
\end{tabular}

Figures in parentheses are in percentage

Table 2

Success rate according to patient age

\begin{tabular}{|l|l|l|}
\hline Patients age (in years) & No. of patients & Success rate \\
\hline $5-15$ & 5 & $4(80)$ \\
\hline $16-40$ & 40 & $37(92.5)$ \\
\hline $41-60$ & 21 & $19(91.6)$ \\
\hline$>60$ & 10 & $9(90)$ \\
\hline
\end{tabular}

Figures in parentheses are in percentage

Table 3

Success rate on the basis of stricture length

\begin{tabular}{|l|l|l|}
\hline Stricture length $\mathbf{( c m )}$ & No. of patients & Success rate \\
\hline$<1$ & 21 & $20(95.23)$ \\
\hline $1-2$ & 24 & $22(91.66)$ \\
\hline $2-3$ & 18 & $16(88.89)$ \\
\hline $3-10$ & 13 & $11(84.61)$ \\
\hline
\end{tabular}

Figures in parentheses are in percentage

Table 4

Success rate according to previous treatment

\begin{tabular}{|l|l|l|}
\hline Previous treatment & No. of patients & Success rate \\
\hline None & 38 & $36(94.73)$ \\
\hline Urethrotomy & 18 & $16(88.88)$ \\
\hline Urethroplasty & 20 & $17(85.0)$ \\
\hline
\end{tabular}

Figures in parentheses are in percentage

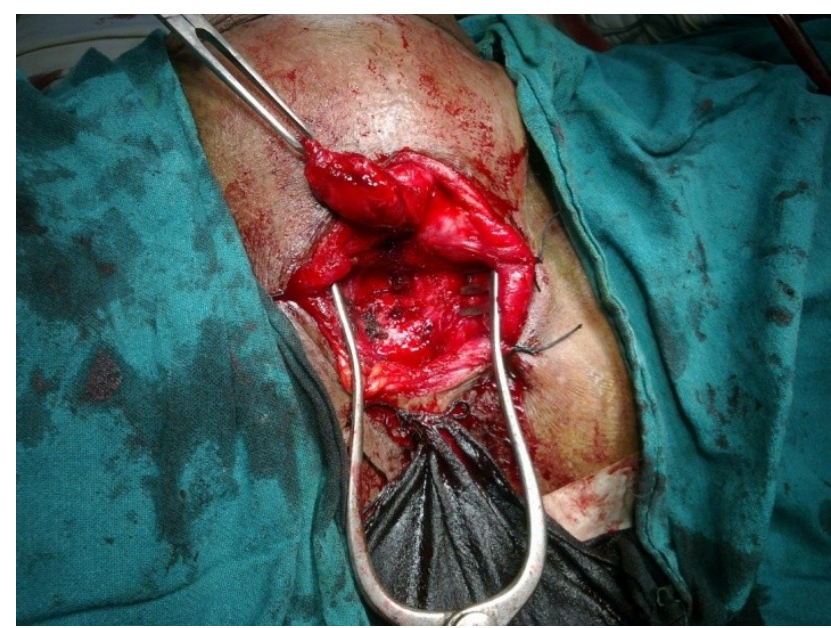

Figure 1:-After crural separation and inferior pubectomy 


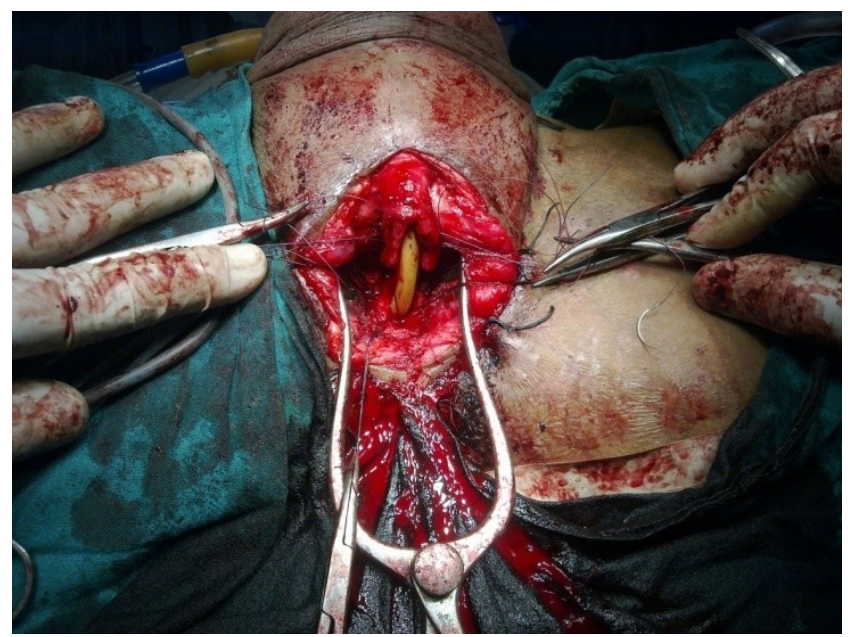

Figure 2:- After proximal mobilisation ready for anastomosis

Postoperative follow-up-

Retrograde urethrogram-After 3 month

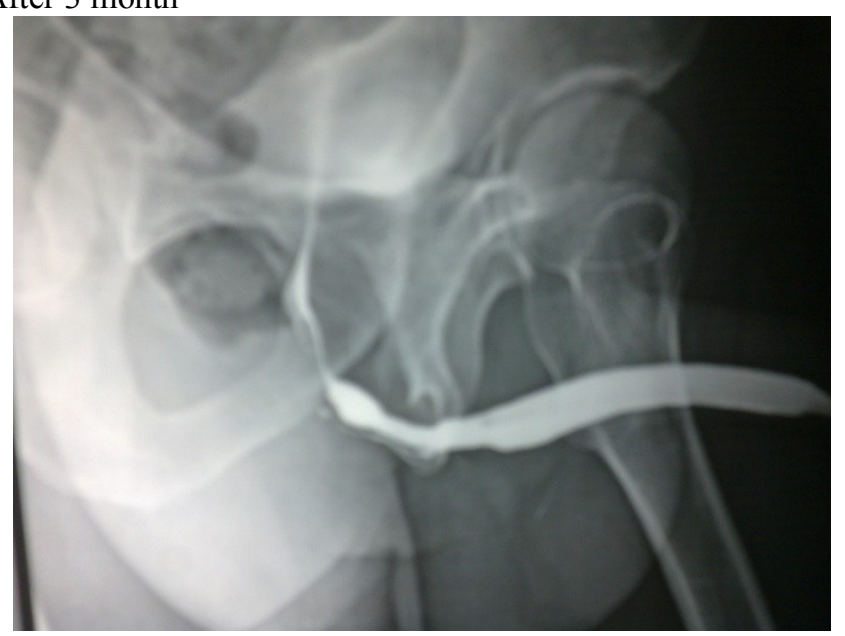

Retrograde urethrogram- after 12 months

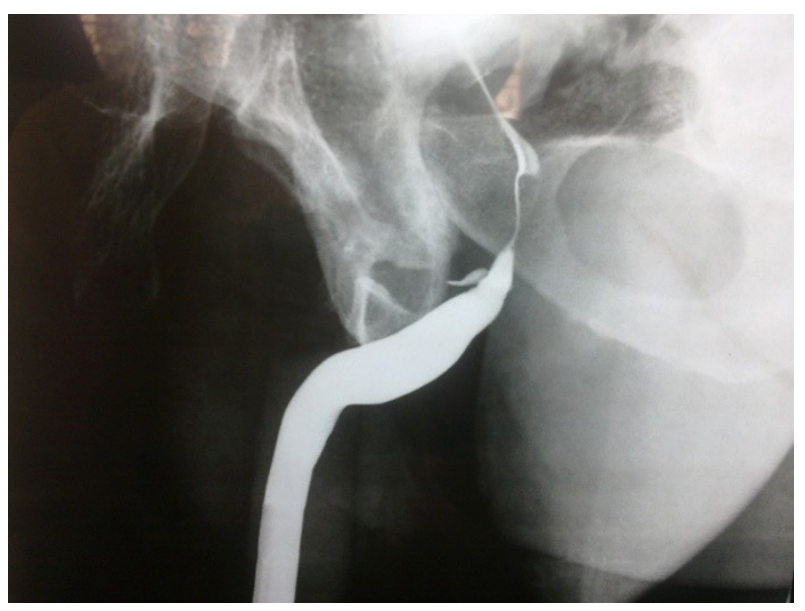

